\title{
Survey of tortoises with urolithiasis in Japan
}

\author{
Yoshinori TAKAMI ${ }^{1) *}$, Hitoshi KOIEYAMA ${ }^{2)}$, Nobuo SASAKI ${ }^{3)}$, Takumi IWAI ${ }^{4)}$, \\ Youki TAKAKI ${ }^{1)}$, Takehiro WATANABE ${ }^{1)}$ and Yasutsugu MIWA ${ }^{3,4)}$
}

\author{
${ }^{1)}$ Verts Animal Hospital, 4-3-1 Morooka, Hakata-ku, Fukuoka-shi, Fukuoka 812-0894, Japan \\ 2) Reptile Clinic, 2F, Morishima Building, 3-2-3 Hongo, Bunkyou-ku, Tokyo 113-0033, Japan \\ ${ }^{3)}$ Vision Vets Group Lab, \#201 NAESHIRO Bldg., 1-24-6 Komagome, Toshima-ku, Tokyo 170-0003, Japan \\ ${ }^{4)}$ Miwa Exotic Animal Hospital, 1-25-5 Komagome, Tosima-ku, Tokyo 170-0003, Japan
}

\section{J. Vet. Med. Sci.}

83(3): 435-440, 2021

doi: 10.1292/jvms.20-0315

Received: 30 May 2020

Accepted: 11 January 2021

Advanced Epub:

21 January 2021
ABSTRACT. Urolithiasis is a disease often seen in tortoises at veterinary hospitals, however there have been no comprehensive research reports of tortoises with urolithiasis in Japan. In this study, we analyzed tortoises diagnosed with urolithiasis at three domestic veterinary hospitals. Based on medical records, we assessed the diagnostic method, species, sex, body weight, dietary history, husbandry, clinical signs, clinical examination, treatment for urolithiasis, and clinical outcome. The total number of cases in the 3 facilities was 101. As for species of tortoises, the most common was the African spurred tortoise (Centrochelys sulcata) with 42 cases $(41.6 \%)$, followed by the Indian star tortoise (Geochelone elegans) with 30 cases (29.7\%). Six other species were confirmed to have calculi. Almost all cases ( 99 cases, $98 \%$ ) had a single calculus, and only 2 had multiple calculi. The prevalence of urolithiasis for the total number of tortoises having visited to one institution during the same period was $5.1 \%$. Of the 86 cases that underwent calculi removal, $64(74.4 \%)$ were successfully removed via the vent, and the efficacy of this method was confirmed. Nineteen cases (22\%) were approached via plastronotomy, among which only 2 died postoperatively. In this study, we could not clarify the relationship between calculi formation and diets or other husbandry factors.

KEY WORDS: plastronotomy, prefemoral fossa incision, Testudinidae family, urolithiasis

Urinary calculi in reptiles have been reported in lizards $[2,15,16,25]$ and chelonians. For chelonians, in particular, there have been several reports, including retrospective studies [1, 4, 8, 10, 11, 20, 21, 24]. In Japan, chelonians have been kept as a pet for a long time, and calculi cases are sometimes found. However, to our knowledge, there have been no detailed domestic reports of urolithiasis in reptiles, including chelonians. Difference in the incidence rate of urolithiasis in different chelonian species has been reported $[10,11,15]$, and the regional difference in species that develop urolithiasis also has been reported [10]. Therefore, detailed survey of urolithiasis in chelonians in Japan should be needed.

Most calculi of chelonians have been confirmed to consist of urate $[1,4,7,10,15,18]$. While there are various hypotheses regarding the cause of calculi formation, its etiology remains unclear [10, 17]. The main treatment is the removal of calculi. Some methods of approach to the urinary system have been proposed for chelonians with shells, but the specific treatment method for each calculus has not been established yet [1, 4, 17-20].

In this study, we conducted a retrospective survey based on medical records on the prevalence, the presence/absence of high prevalence species, clinical signs, causes of development, treatment method, and clinical outcome of urolithiasis in tortoises belonging to the Testudinidae family in Japan. The findings were compared to those in previous reports. The duration of this study was more than 2 decades, although some species such as Indian star tortoise had been registered in CITES during this period, we confirmed the tortoises that were illegally kept at the time of the examination were not included in this study.

\section{MATERIALS AND METHODS}

We reviewed medical records of three domestic veterinary hospitals from April 1998 to October 2019, and retrospectively surveyed the clinical features of tortoises diagnosed with urolithiasis belonging to the Testudinidae family. The diagnosis of urolithiasis was made based on visual confirmation of calculi via the vent, or by radiography.

Based on medical records, we investigated the following for each case: the method of urolithiasis diagnosis, species, sex, body weight, dietary history, husbandry, clinical signs, clinical examination, treatment of urolithiasis, and clinical outcome. The species of tortoises were determined by the common name provided by the owner. Sex was determined based on physical features 


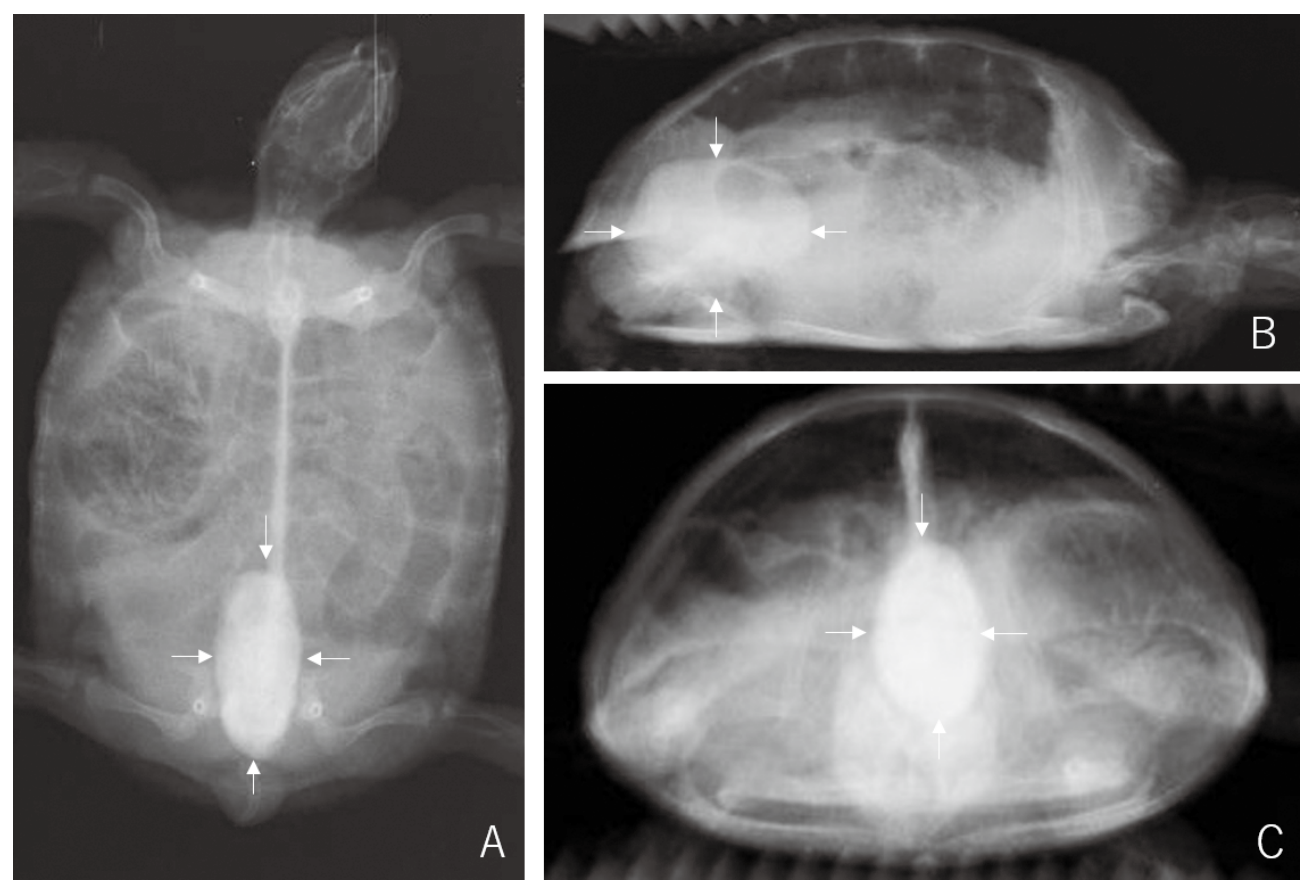

Fig. 1. Radiographs of Greek tortoise with urolithiasis. A, dorsoventral view, B, lateral view $\mathrm{C}$, cranial-caudal views. A single radiopaque structure (arrow) is in contact with the pelvic canal.

such as the shape of plastrons of each species, confirmation of phallus, and the presence or absence of ovaries at the time of ultrasonography or coeliotomy. Those without description in the medical record or whose physical features could not be confirmed were categorized as unclear. The dietary history was classified into the following: natural food only diet including leafy vegetables, field grass and fruits; diet including artificial food, and unclear. As for husbandry, we investigated water sources, and whether they were kept indoors or outdoors. Water sources were classified as follows: water supply on bathing, permanently installed water bowl, no water source, and unclear. For cases subjected to clinical examination, we compared the following blood biochemistry data to the reference ranges $[3,5,13]$ of the same or related species: uric acid, total calcium, phosphorus, glucose, urea nitrogen, total protein, albumin, globulin, sodium, potassium, chloride, aspartate transaminase, alkaline phosphatase, creatine kinase, triglyceride, and total cholesterol. The position and number of calculi were recorded based on the radiographs comprising of at least three directions (dorsoventral view, lateral view, cranial-caudal views) (Fig. 1).

The method of calculi removal was categorized by the following approaches: vent, plastronotomy, and prefemoral fossa incision, and clinical outcomes in each group were reviewed based on medical records. Regarding the type of removed calculi, the submitted number for analysis and their analyzed results were reviewed.

The prevalence of urolithiasis was calculated at one of the three facilities where the total number of tortoises seen during the survey period could be retrieved from the medical records. The prevalence of urolithiasis in tortoises seen at the facility was calculated by dividing the number of tortoises with urolithiasis by the total number of tortoises seen at the facility during the same period.

\section{RESULTS}

A total of 101 tortoises were assessed in this study. The diagnosis of urolithiasis was confirmed by radiography in 63 cases, and by visual inspection of calculi via the vent in 38 cases. Sex, body weight, dietary history, water sources, and husbandry for each species are summarized in Table 1. African spurred tortoises (Centrochelys sulcata) with 42 cases (41.6\%) were the highest, followed by 30 cases (29.7\%) of Indian star tortoise (Geochelone elegans), 9 cases (8.9\%) of Russian tortoise (Testudo horsfieldii), 7 cases $(6.9 \%)$ of Greek tortoise (Testudo graeca), 4 cases (3.9\%) of Burmese star tortoise (Geochelone platynota), 3 cases (2.9\%) of Marginated tortoise (Testudo marginata), 1 each case $(0.9 \%)$ of Hermann's tortoise (Testudo hermanni) and Kleinmann's tortoise (Testudo kleinmanni), and 4 hybrids (3.9\%) of African spurred tortoises and Leopard tortoise (Stigmochely spardalis). As for the sex of tortoises, $32(31.6 \%)$ were males, $14(13.9 \%)$ were females, and $55(54.5 \%)$ were unclear. The body weight at the time of diagnosis was 30 to $17,800 \mathrm{~g}$ (median $328 \mathrm{~g}$ ).

Of the 101 cases, $93(92.0 \%)$ had a clear dietary history, of which 54 were given natural food only, containing leafy vegetables, field grass, and fruits. Thirty-nine cases were given a diet containing artificial food such as pellets.

Of the 67 (66.3\%) with clear water sources, the method of water supply was as follows: 39 (58.2\%) baths, $17(25.3 \%)$ permanently installed water bowl, $7(1 \%)$ baths and water bowl, and $4(0.6 \%)$ with no source of water supply. Of the $36(35.6 \%)$ cases with clear keeping location, 34 (94.4\%) were indoors, 1 (2.9\%) was outdoors, and 1 (2.9\%) was kept in both locations. 
Table 1. Sex, body weight, dietary history, water sources, and husbandry by species

\begin{tabular}{|c|c|c|c|c|c|}
\hline Species & $\operatorname{Sex}(n)$ & $\mathrm{Bw}(\mathrm{g})$ & $\mathrm{DH}(\mathrm{n})$ & WS (n) & Husbandry (n) \\
\hline \multirow{5}{*}{ Centrochelys sulcata } & $\mathrm{M}(10)$ & $82-17,800$ & NF (23) & W (7) & $\mathrm{I}(10)$ \\
\hline & $\mathrm{F}(5)$ & & $\mathrm{AF}(15)$ & B (20) & $\mathrm{O}(1)$ \\
\hline & $\mathrm{U}(27)$ & & $\mathrm{U}(4)$ & WB (1) & IO (1) \\
\hline & & & & N (2) & $\mathrm{U}(30)$ \\
\hline & & & & $\mathrm{U}(12)$ & \\
\hline \multirow[t]{5}{*}{ Geochelone elegans } & M (11) & $38-1,600$ & NF (9) & $\mathrm{W}(2)$ & I (13) \\
\hline & $\mathrm{F}(6)$ & & $\mathrm{AF}(18)$ & $\mathrm{B}(9)$ & $\mathrm{O}(0)$ \\
\hline & $\mathrm{U}(13)$ & & $\mathrm{U}(3)$ & WB (4) & $\mathrm{IO}(0)$ \\
\hline & & & & N (1) & $\mathrm{U}(17)$ \\
\hline & & & & $\mathrm{U}(14)$ & \\
\hline \multirow[t]{5}{*}{ Testudo horsfieldii } & $M(5)$ & $30-957$ & NF (5) & W (3) & I (5) \\
\hline & $\mathrm{F}(0)$ & & $\mathrm{AF}(3)$ & B (4) & $\mathrm{O}(0)$ \\
\hline & U (4) & & $\mathrm{U}(1)$ & WB (0) & IO $(0)$ \\
\hline & & & & $\mathrm{N}(0)$ & $\mathrm{U}(4)$ \\
\hline & & & & $\mathrm{U}(2)$ & \\
\hline \multirow[t]{5}{*}{ Testudo graeca } & M (1) & $68-521$ & NF (5) & W (3) & I (2) \\
\hline & $\mathrm{F}(0)$ & & $\mathrm{AF}(2)$ & $\mathrm{B}(1)$ & $\mathrm{O}(0)$ \\
\hline & $\mathrm{U}(6)$ & & $\mathrm{U}(0)$ & WB (1) & IO (0) \\
\hline & & & & $\mathrm{N}(0)$ & $\mathrm{U}(5)$ \\
\hline & & & & $\mathrm{U}(2)$ & \\
\hline \multirow[t]{5}{*}{ Geochelone platynota } & M (1) & $56-594$ & NF (4) & $\mathrm{W}(0)$ & I (3) \\
\hline & $\mathrm{F}(0)$ & & $\mathrm{AF}(0)$ & B (0) & $\mathrm{O}(0)$ \\
\hline & $\mathrm{U}(3)$ & & $\mathrm{U}(0)$ & WB (1) & $\mathrm{IO}(0)$ \\
\hline & & & & $\mathrm{N}(0)$ & $\mathrm{U}(1)$ \\
\hline & & & & U (3) & \\
\hline \multirow[t]{5}{*}{ Testudo marginata } & $\mathrm{M}(0)$ & $54-366$ & NF (2) & $\mathrm{W}(2)$ & $\mathrm{I}(0)$ \\
\hline & $\mathrm{F}(2)$ & & $\mathrm{AF}(1)$ & B (1) & $\mathrm{O}(0)$ \\
\hline & $\mathrm{U}(1)$ & & $\mathrm{U}(0)$ & WB (0) & $\mathrm{IO}(0)$ \\
\hline & & & & $\mathrm{N}(0)$ & U (3) \\
\hline & & & & $\mathrm{U}(0)$ & \\
\hline \multirow[t]{5}{*}{ Testudo hermanni } & $\mathrm{M}(0)$ & 61 & NF (1) & $\mathrm{W}(0)$ & $\mathrm{I}(1)$ \\
\hline & $\mathrm{F}(0)$ & & $\mathrm{AF}(0)$ & B (0) & $\mathrm{O}(0)$ \\
\hline & $\mathrm{U}(1)$ & & $\mathrm{U}(0)$ & WB (0) & $\mathrm{IO}(0)$ \\
\hline & & & & $\mathrm{N}(0)$ & $\mathrm{U}(0)$ \\
\hline & & & & $\mathrm{U}(1)$ & \\
\hline \multirow[t]{5}{*}{ Testudo kleinmanni } & $\mathrm{M}(0)$ & 164 & NF (1) & $\mathrm{W}(0)$ & $\mathrm{I}(0)$ \\
\hline & $\mathrm{F}(1)$ & & $\mathrm{AF}(0)$ & B (0) & $\mathrm{O}(0)$ \\
\hline & $\mathrm{U}(0)$ & & $\mathrm{U}(0)$ & WB (0) & $\mathrm{IO}(0)$ \\
\hline & & & & $\mathrm{N}(1)$ & $\mathrm{U}(1)$ \\
\hline & & & & $\mathrm{U}(0)$ & \\
\hline \multirow[t]{5}{*}{ Centrochelys sulcate $\times$ Stigmochelys pardalis } & $\mathrm{M}(4)$ & $392-1,130$ & NF (4) & $\mathrm{W}(0)$ & $\mathrm{I}(0)$ \\
\hline & $\mathrm{F}(0)$ & & $\mathrm{AF}(0)$ & B (4) & $\mathrm{O}(0)$ \\
\hline & $\mathrm{U}(0)$ & & $\mathrm{U}(0)$ & WB $(0)$ & $\mathrm{IO}(0)$ \\
\hline & & & & $\mathrm{N}(0)$ & $\mathrm{U}(4)$ \\
\hline & & & & $\mathrm{U}(0)$ & \\
\hline
\end{tabular}

M, Male; F, Female; U, Unclear; NF, Natural food; AF, Artificial food; W, Water bowl; B, Baths; WB, Water bowl and Baths; N, Nothing; I, Indoors; O, Outdoors; IO, Indoors and outdoors.

As for the clinical signs, there were 54 cases of straining related to excretion, 45 anorexia, 13 lethargy, 4 cloacal prolapse, 2 phallus prolapse, 1 wasting, 1 diarrhea, and 1 nasal discharge. Twelve (11.8\%) tortoises had no apparent clinical signs.

Twenty one out of 101 cases received blood biochemistry examinations; they were 9 African spurred tortoises, 7 Indian star tortoises, 1 Russian tortoise, 1 Greek tortoise, 1 Burmese star tortoise, and 2 hybrids of African spurred tortoise and Leopard tortoise. The results are shown in Table 2. The results of 6 tortoises were found to have the following deviations from the reported reference range $[3,5,13]$ of the same species or related species. There were 4 cases (No. 2, 7, 9, 20) with hyperuricemia (>18 mg/ $\mathrm{dl}$, one of which was $>25 \mathrm{mg} / \mathrm{dl}$ ). Three of them were African spurred tortoises, and one was a hybrid of African spurred tortoise and Leopard tortoise. Two cases (No. 9, 10), including an African spurred tortoise and an Indian star tortoise, had abnormally 
Table 2. Blood biochemical variables for 21 tortoises with urolithiasis

\begin{tabular}{|c|c|c|c|c|c|c|c|c|c|c|c|c|c|c|c|c|}
\hline Species, No & $\begin{array}{c}\mathrm{UA} \\
(\mathrm{mg} / \mathrm{dl})\end{array}$ & $\begin{array}{c}\mathrm{Ca} \\
(\mathrm{mg} / \mathrm{dl})\end{array}$ & $\begin{array}{c}\mathrm{P} \\
(\mathrm{mg} / \mathrm{dl})\end{array}$ & $\begin{array}{c}\text { Glu } \\
\text { (mg/dl) }\end{array}$ & $\begin{array}{c}\mathrm{BUN} \\
(\mathrm{mg} / \mathrm{dl})\end{array}$ & $\begin{array}{c}\mathrm{TP} \\
(\mathrm{g} / \mathrm{dl})\end{array}$ & $\begin{array}{l}\text { Alb } \\
(\mathrm{g} / \mathrm{dl})\end{array}$ & $\begin{array}{l}\text { Glb } \\
(\mathrm{g} / \mathrm{dl})\end{array}$ & $\begin{array}{c}\mathrm{Na} \\
(\mathrm{mmol} / \mathrm{l})\end{array}$ & $\underset{(\mathrm{mmol} / \mathrm{l})}{\mathrm{K}}$ & $\begin{array}{c}\mathrm{Cl} \\
(\mathrm{mmol} / \mathrm{l})\end{array}$ & $\begin{array}{l}\text { AST } \\
(\mathrm{U} / 1)\end{array}$ & $\begin{array}{l}\text { ALP } \\
\text { (U/l) }\end{array}$ & $\begin{array}{c}\mathrm{Ck} \\
(\mathrm{U} / \mathrm{l})\end{array}$ & $\underset{(\mathrm{mg} / \mathrm{dl})}{\mathrm{TG}}$ & $\begin{array}{c}\text { Tcho } \\
(\mathrm{mg} / \mathrm{dl})\end{array}$ \\
\hline Centrochelys sulcata 1, No. 1 & 7.1 & 9.1 & 6.5 & 91 & 9.8 & 2.2 & 1 & 0 & 135 & 6.1 & & 93 & & 1,395 & & \\
\hline Centrochelys sulcata 2, №. 2 & $>18^{*}$ & 15 & 2.7 & 169 & & 5.8 & & & 131 & 7.1 & 96 & 177 & 123 & & & \\
\hline Centrochelys sulcata 3 , No. 3 & 3.9 & 15.7 & 3.9 & 219 & 0.1 & 4.6 & & & & & & 164 & 168 & & & \\
\hline Centrochelys sulcata 4 , No. 4 & 8.2 & 12.4 & 3.5 & 133 & 1.9 & 4.6 & 2.2 & & 131 & 3.4 & 97 & 132 & 81 & & & 95 \\
\hline Centrochelys sulcata 5 , No. 5 & 6.7 & 13.3 & 3 & 121 & 2.2 & 3.7 & 1.9 & 1.8 & 127 & 7.6 & & 127 & & 595 & 140 & \\
\hline Centrochelys sulcata 6 , No. 6 & 1 & 8.7 & 1.2 & 97 & 2.5 & 4 & & & & & & 16 & & 104 & & \\
\hline Centrochelys sulcata 7, No. 7 & $>25^{*}$ & 15.7 & 4.3 & $541^{*}$ & & 5.8 & 1.2 & 4.6 & $<110$ & $>8.5$ & & 191 & & 4,111 & & \\
\hline Centrochelys sulcata 8, No. 8 & 10.5 & 9.9 & 1.9 & & & 2.8 & & & & & & & & & & \\
\hline Centrochelys sulcata 9, No. 9 & $>18^{*}$ & $>16^{*}$ & 2.3 & & $56.2^{*}$ & 2.5 & & & & & & & & & & \\
\hline Geochelone elegans 1 , No. 10 & 2.4 & 8.2 & 4.9 & 57 & $100.3^{*}$ & 3.2 & 0.7 & & 141 & 3.2 & 112 & 26 & & & & \\
\hline Geochelone elegans 2, No. 11 & 13 & 10 & 3.4 & 107 & 8.1 & 4.5 & 1.3 & 3.2 & 124 & 7.3 & & 114 & & 595 & 73 & \\
\hline Geochelone elegans 3, No. 12 & 4.6 & 14.9 & 3.4 & 145 & 2.2 & 5.7 & 2 & 3.8 & 123 & 4.8 & & 57 & & 340 & & \\
\hline Geochelone elegans 4, No. 13 & 11 & 10.5 & 2.2 & & & 5 & & & & & & & & & & \\
\hline Geochelone elegans 5, No. 14 & 2.1 & 7.5 & 1.7 & & & $<2.0$ & & & & & & & & & & \\
\hline Geochelone elegans 6, No. 15 & 8.4 & 6 & 1 & & & & & & & & & & & & & \\
\hline Geochelone elegans 7, No. 16 & 8.9 & & & & & & & & & & & & & & & \\
\hline Testudo horsfieldii, No. 17 & 9.3 & 9.9 & $7.8^{*}$ & 85 & 7 & 1.8 & 1.3 & 0 & 128 & 4.6 & & 40 & & 436 & & \\
\hline Testudo graeca, No. 18 & 3 & 14 & 4.7 & 170 & 3.5 & 4 & 1.8 & 2.3 & 111 & 7.7 & & 154 & & 252 & 40 & \\
\hline Geochelone platynota, No. 19 & 4.5 & 7.4 & 0.9 & & & & & & & & & & & & & \\
\hline Hybrid20, No. 20 & $>18^{*}$ & 12.7 & 2.8 & & & 3.2 & & & & & & & & & & \\
\hline Hybrid21, No. 21 & 6.7 & 12.3 & 1.1 & & & & & & & & & & & & & \\
\hline
\end{tabular}

*Values out of the reference ranges. UA, Uric Acid; Ca, Total calcium; P, Phosphorous; Glu, Glucose; BUN, Blood Urea nitrogen; TP, Total protein; Alb, Albumin; Glb, Globulin; AST, Aspartate transaminase; ALP, Alkaline phosphatase; Ck, Creatinkinaze; TG, Triglyceride; Tcho, Total cholesterol.

increased blood urea nitrogen concentrations (100.3 mg/dl and $56.2 \mathrm{mg} / \mathrm{dl})$. Hyperphosphatemia $(7.8 \mathrm{mg} / \mathrm{dl})$ and hyperglycemia $(541 \mathrm{mg} / \mathrm{dl})$ were seen in a Russian tortoise (No. 17) and an African spurred tortoise (No. 7), respectively. The results of 15 cases were within the reference range (Table 2).

Of the 63 cases that underwent radiography, 61 had a single calculus and two cases had more than one, with 2 and 4 cystic calculi. The location of calculi was urinary bladder and cloaca in 50 and 13 cases, respectively. Among those with cystic calculi, 6 were found to have calculi in contact with the pelvic canal (Fig. 1).

Eighty-six out of 101 cases $(85.1 \%)$ received surgical removal of calculi. Surgical approaches were divided into 3: via the vent in 64 cases, via the plastronotomy in 19 cases, and via the prefemoral fossa incision in 3 cases, respectively. Other 15 cases $(14.9 \%)$ were untreated, among which small calculus seemed to be naturally excreted in 8 cases on radiography.

There were 19 cases of cystic calculi confirmed on radiography that underwent the vent approach. Among these, calculi were in contact with the pelvic canal on the radiographs in 6 cases, and in remaining 13 cases, calculi were located either in the center or the left or right lobe of the urinary bladder. In addition, 13 tortoises were confirmed to have cloacal calculi, and calculi were visually confirmed via the vent in 32 cases.

Among the vent-approached cases, 43 (67.2\%) exhibited straining related to excretion as a clinical sign. On the other hand, of the 19 cases treated with plastronotomy, only $3(15.8 \%)$ exhibited straining related to excretion.

Among 86 cases receiving surgical removal, there were 3 cases (3.4\%) of death during the perioperative period in this study. These 3 cases were all African spurred tortoise. One case had severe deterioration of overall health, hyperuricemia (Uric Acid $>18$ $\mathrm{mg} / \mathrm{dl})$, and an abnormally increased blood urea nitrogen concentration $(56.2 \mathrm{mg} / \mathrm{dl})$.

The death occurred during treatment via the vent approach under no anesthesia.

Two other cases receiving the surgery via plastronotomy died one day after the surgeries. One was found to have coelomitis associated with severe adhesion due to urinary bladder laceration, and the other was confirmed to have coelomic fluid accumulation and intestinal necrosis during the perioperative period, although their relationship with calculi was unknown.

Among 86 cases receiving surgery, 23 visited the hospital and the prognosis was confirmed at their last visits to the hospital. They were all clinically normal at their last visits. Surgical calculi removal was done via the vent in 9 cases ( 3 African spurred tortoises, 3 Indian star tortoises, 1 Russian tortoise, 1 Greek tortoise and 1 Hermann's tortoise), via plastronotomy in 11 cases (6 African spurred tortoises, 3 Indian star tortoises, 1 Russian tortoise and 1 Greek tortoise), and via prefemoral fossa incision (one each of African spurred tortoise, Indian star tortoise, and Russian tortoise).

The duration between the date of calculi removal and those of the last visit to the hospitals was 12-1,925 days (average 622 
days) [via the vent], 13-1,135 days (average 337 days) [via plastronotomy], 203-1,925 days (average 944 days) [via prefemoral fossa incision], respectively.

Removed calculi from 66 tortoises were analyzed, and they were all identified as ammonium acid urate calculi. The total number of tortoises seen at one institution from 2007 to 2019 was 589, of which 30 were diagnosed with urolithiasis with the prevalence of $5.1 \%$.

\section{DISCUSSION}

In this study, we evaluated the prevalence of urinary calculi in tortoises that were seen at veterinary hospitals. As for the species of tortoises in this study, there was a few species predisposition; the most common species was African spurred tortoise (Centrochelys sulcata) which occupied 41.6\% (42 cases) and the second most common species was the Indian star tortoise (Geochelone elegans). African spurred tortoise was reported to be the second-highest prevalence in a study from America and in some other case reports $[1,10,20]$. While, according to the published literature from Europe, Testudo and Geochelone were the two species with the highest prevalence of urolithiasis $[11,15]$.

These species were also predominant species in this study, and these regional variations may be related to the species popularity as pet tortoises by countries, although the population of these species in the countries was not clear.

All uroliths analyzed in this study were composed of ammonium acid urate, similar to the previous reports [10]. Other types of calculi containing struvite, calcium phosphate, oxalate, and calcium carbonate have been reported in aquatic species [8, 9, 21, 23]. It has been reported that nitrogen metabolite differs depending on the species. In aquatic species, nitrogen metabolite has a higher proportion of urea and ammonia than urate [22]. In terrestrial species, Indian star tortoise and Testudinidae family mainly excrete urate [22], and other species such as the Forest hinge-back tortoise (Kinixys erosa) and the Yellow-footed tortoise (Chelonoidis denticulatus) are known to have a higher proportion of urea than urate. Furthermore, it has been confirmed that even among the same species, conversion of urea to urate or vice versa occurs with changes in temperature and water supply. It has also been found that urea to urate conversion occurs when there is inadequate moisture [12]. It was, therefore, speculated that among the Testudinidae family, the prevalence of calculi differs by species.

Calculi of tortoises are thought to develop secondary to various disorders such as vitamin A and D deficiencies, and excessive intake of dietary calcium, protein, or oxalates [17]. Regarding diet, 6 out of 40 cases were fed monkey or dog food in a previous report. It was suggested that inappropriate diet may have contributed to calculi formation [10]. In addition, it has been suggested that chronic dehydration, inappropriate heat retention, and lack of water source cause an increase in water absorption from the urinary bladder and colon. This further supersaturates and concentrates urate in the urinary bladder, leading to calculi formation [10]. From the results of 93 cases $(92.0 \%)$ for which information on dietary history was obtained in this study, however there was no record of the diet with excessive animal protein, and we did not find any cases with inappropriate diet. Therefore, we confirmed that calculi may occur even when an appropriate diet is provided. Moreover, since most of the tortoises in this study were kept in indoor cages, lack of exercise may have contributed to the development of calculi. In addition, the relationship with the development of calculi could not be clarified from the results of the water supply in this study.

Of the 46 cases whose sex could be identified in this study, 32 (68.0\%) were males. The incidence of calculi in dogs and humans is also higher in males, and in humans, sex hormones are thought to be involved in its pathogenesis [6,14]. Given the fact that there have been no report on the etiology of sex hormones and calculi development in tortoises and that the number of sex identifiable cases was limited in this study, the association between calculi development in tortoises and sex difference requires further research.

The most common clinical signs in this study were straining related to excretion and was seen in 54 cases (53.4\%), followed by anorexia, seen in 45 cases $(44.5 \%)$. However, there was a large difference in clinical signs compared to previous studies that reported 1 case $(2.5 \%)$ of straining related to excretion and $10(25 \%)$ cases of anorexia [10]. This may be partly because many are kept outdoors overseas, whereas in Japan many are kept indoors. This leads to the ease in recognizing abnormal excretion, suggesting that it is a clinical sign to suspect urolithiasis in tortoises. On the other hand, this study also found several cases in which straining related to excretion was not seen, even with a large calculi present [10].

Of 63 cases that underwent radiography, $50(79.4 \%)$ and $13(20.6 \%)$ were found to have calculi in the urinary bladder and cloaca, respectively. This result was similar to the previously reported rates of cystic calculi (83.3\%) and cloacal calculi (17.7\%) [10]. In this study, 38 cases of calculi were visually confirmed via the vent without radiography, and the rates of cloaca calculi were further increased if these cases were added. Cloacal calculi are likely a result of cystic calculi that have migrated during micturition and it was confirmed that the relatively high rate of calculi would remain in the cloaca even passed through the urinary bladder in tortoises.

Of the 21 cases $(20.7 \%)$ with blood biochemistry results, abnormalities were found in 6 cases. While hyperuricemia was observed in 4 of these cases, we could not clarify the causal relationship with the development of calculi. To date, there has been a report of an abnormally increased blood urea nitrogen concentrations and hyperuricemia in tortoises that died from urate calculi, as well as a report that found almost no abnormalities in blood biochemistry of tortoises with calculi [7, 10]. The result of this study was similar to the latter. However, the interpretation of chelonians' blood biochemistry differs greatly depending on the season, sex, sexual maturity, nutrition, environment, and husbandry. In addition, since the number of cases in this study was small, the effectiveness of the blood chemistry test for the diagnosis of urolithiasis in tortoises is debatable.

Of the 86 tortoises that had their calculi removed in this study, the most frequent approach was via the vent (64 cases, $74.4 \%)$. 
On the other hand, in a previous study of 17 chelonians with calculi removal, plastronotomy (12 cases, 70.6\%) was the most common approach [10].

In this study, the percentage of cases presenting with straining was higher in the vent-approached cases. These results suggested that straining on excretion is more often found when calculi are present in the pelvic canal.

To date, the vent approach has been limitedly used for cloacal calculi [20]. However, the results of this study show that calculi can be removed via the vent if they partially protrude into the cloaca or are caught in the pelvic canal. Furthermore, calculi which are present in the urinary bladder can be removed via vent if they can be reached and crushed by the forceps. Plastronotomy is a highly invasive surgery for chelonians, and our findings suggest that approach via the vent may be an option that can be applied to more cases when removing urinary calculi in tortoises.

The three cases of death during the perioperative period had severe intraoperative findings and blood biochemistry examination results. These results may indicate tortoises with urolithiasis showing deterioration of overall health are the high risk patients for surgery to remove calculi.

In previous studies, 4 of 17 cases $(23.5 \%)$ had died postoperatively, 2 of which were due to plastronotomy [10]. This study showed that although the clinical outcome of urolithiasis including surgery is not poor, the following scenarios require caution in terms of prognosis: cases with damaged urinary bladder by significantly enlarged calculi that had been left untreated and cases with preoperative deterioration of the general condition and obvious abnormalities in blood biochemistry.

In this study, the prevalence of urolithiasis of tortoises evaluated at one facility for 12 years was 5.2\%, and this was similar to the previously reported prevalence from USA [10]. In future studies, it will be necessary to investigate the factors that lead to the formation of stones in tortoises, that could not be clarified in this study.

POTENTIAL CONFLICTS OF INTEREST. The authors have nothing to disclose.

\section{REFERENCES}

1. Amat, A. C., Gabriel, B. and Chee, N. W. 2012. Cystic calculi removal in African spurred tortoise (Geochelone sulcata) using transplastron coeliotomy. Vet. World 5: 489-492. [CrossRef]

2. Anderson, N. L., Williams, J., Sagartz, J. E. and Barnewall, R. 1996. Ovarian teratoma in a green iguana (Iguana iguana). J. Zoo Wildl. Med. 27: 90-95.

3. Eshar, D., Gancz, A. Y., Avni-Magen, N., Wagshal, E., Pohlman, L. M. and Mitchell, M. A. 2016. Selected plasma biochemistry analytes of healthy captive sulcata (African spurred) tortoises (Centrochelys sulcata). J. Zoo Wildl. Med. 47: 993-999. [Medline] [CrossRef]

4. Frye, F. L. 1972. Surgical removal of a cystic calculus from a desert tortoise. J. Am. Vet. Med. Assoc. 161: 600-602. [Medline]

5. Gibbons, P. M., Whitaker, B. R., Carpenter, J. W., McDermott, C. T., Klaphake, E. and Sladky, K. K. 2019. Hematology and Biochemistry Tables. pp. 333-350. In: Mader's Reptile and Amphibian Medicine and Surgery, 3rd ed. (Divers, S. J. and Stahl, S. J. eds.), Elsevier, St. Louis.

6. Hesse, A. 1990. Canine urolithiasis: Epidemiology and analysis of urinary calculi. J. Small Anim. Pract. 31: 599-604. [CrossRef]

7. Homer, B. L., Berry, K. H., Brown, M. B., Ellis, G. and Jacobson, E. R. 1998. Pathology of diseases in wild desert tortoises from California. J. Wildl. Dis. 34: 508-523. [Medline] [CrossRef]

8. Innis, C. and Kincaid, A. 1999. Bilateral calcium phosphate ureteroliths and spirorchid trematode infection in a red-eared slider turtle, Trachemys scripta elegans, with a review of the pathology of spirorchidiasis. Bull. Assoc. Reptilian. Amphibian. Vet 9: 32-35. [CrossRef]

9. Jacobson, E. R., Berry, K. H., Stacy, B., Huzella, L. M., Kalasinsky, V. F., Fleetwood, M. L. and Mense, M. G. 2009. Oxalosis in wild desert tortoises, Gopherus agassizii. J. Wildl. Dis. 45: 982-988. [Medline] [CrossRef]

10. Keller, K. A., Hawkins, M. G., Weber, E. P. 3rd., Ruby, A. L., Guzman, D. S. and Westropp, J. L. 2015. Diagnosis and treatment of urolithiasis in client-owned chelonians: 40 cases (1987-2012). J. Am. Vet. Med. Assoc. 247: 650-658. [Medline] [CrossRef]

11. Keymer, I. F. 1978. Diseases of chelonians: (1) Necropsy survey of tortoises. Vet. Rec. 103: 548-552. [Medline] [CrossRef]

12. Khalil, F. and Haggag, G. 1955. Ureotelism and uricotelism in tortoises. J. Exp. Zool. 130: 423-432. [CrossRef]

13. Klaphake, E., Gibbons, P. M., Sladky, K. K. and Carpenter, J. W. 2018. Reptiles. pp. 82-166. In: Exotic Animal Formulary, 5th ed. (Carpenter, J. W. ed), Elsevier: St. Louis.

14. Kohri, K., Kodama, M., Ishikawa, Y., Katayama, Y., Takada, M., Katoh, Y., Kataoka, K., Iguchi, M. and Kurita, T. 1991. Relationship between metabolic acidosis and calcium phosphate urinary stone formation in women. Int. Urol. Nephrol. 23: 307-316. [Medline] [CrossRef]

15. Kölle, P., Hoffman, R., Wolters, M. and Hesse, M. A. 2001. Cystic calculi in reptiles. Proceedings. Assoc. Reptile. Amphib. Vet 191-192.

16. Kwantes, L. J. 1992. Surgical correction of cystic urolithiasis in an iguana. Can. Vet. J. 33: 752-753. [Medline]

17. Mader, D. 2005. Calculi: urinary. pp.763-771. In: Reptile Medicine and Surgery, 2nd ed. (Mader, D. R. ed.), Elsevier, St. Louis.

18. Mader, D. R, Ling., G. V. and Ruby, A. L. 1999. Cystic calculi in the California desert tortoise (Gopherus agassizii): evaluation of 100 cases. Proceedings. Assoc. Reptile. Amphib. Vet 81-82.

19. Mangone, B. and Johnson, J. D. 1998. Surgical removal of cystic calculi via the inguinal fossa and other techniques applicable to the approach in the desert tortoise, Gopherus agassizii, Proceedings. Assoc. Reptile. Amphib. Vet 87-88.

20. Mans, C. and Sladky, K. K. 2012. Endoscopically guided removal of cloacal calculi in three African spurred tortoises (Geochelone sulcata). J. Am. Vet. Med. Assoc. 240: 869-875. [Medline] [CrossRef]

21. McKown, R. D. 1998. A cystic calculus from a wild western spiny softshell turtle (Apalone [Trionyx] spiniferus hartwegi). J. Zoo Wildl. Med. 29: 347. [Medline]

22. Moyle, V. 1949. Nitrogenous excretion in Chelonian reptiles. Biochem. J. 44: 581-584. [Medline] [CrossRef]

23. Osborne, C. A., Albasan, H., Lulich, J. P., Nwaokorie, E., Koehler, L. A. and Ulrich, L. K. 2009. Quantitative analysis of 4468 uroliths retrieved from farm animals, exotic species, and wildlife submitted to the Minnesota Urolith Center: 1981 to 2007. Vet. Clin. North Am. Small Anim. Pract. 39: 65-78. [Medline] [CrossRef]

24. Rowland, M. 2013. Plastron osteotomy to remove cystic calculus from Indian star tortoise. Vet. Times (Peterb.) 43: 12-13.

25. Wolf, K. N., Troan, B. V. and DeVoe, R. 2008. Chronic urolithiasis and subsequent cystectomy in a San Esteban Island Chuckwalla, Sauromalus varius. J. Herpetological Med. Surg. 18: 106-112. [CrossRef] 